\title{
Evaluation of Medium Voltage Network for Propagation of Supraharmonics Resonance
}

\author{
Shimi Sudha Letha *, Angela Espin Delgado (1), Sarah K. Rönnberg and Math H. J. Bollen (i) \\ Department of Engineering Sciences and Mathematics, Luleå University of Technology, 93187 Skellefteå, Sweden; \\ angela.espin.delgado@ltu.se (A.E.D.); sarah.ronnberg@ltu.se (S.K.R.); math.bollen@ltu.se (M.H.J.B.) \\ * Correspondence: shimi.sudha.letha@ltu.se
}

Citation: Letha, S.S.; Delgado, A.E.; Rönnberg, S.K.; Bollen, M.H.J.

Evaluation of Medium Voltage Network for Propagation of Supraharmonics Resonance. Energies 2021, 14, 1093. https://doi.org/ $10.3390 /$ en14041093

Academic Editor: José Manuel Ribeiro Baptista

Received: 15 January 2021

Accepted: 17 February 2021

Published: 19 February 2021

Publisher's Note: MDPI stays neutral with regard to jurisdictional claims in published maps and institutional affiliations.

Copyright: (c) 2021 by the authors. Licensee MDPI, Basel, Switzerland. This article is an open access article distributed under the terms and conditions of the Creative Commons Attribution (CC BY) license (https:/ / creativecommons.org/licenses/by/ $4.0 /)$.

\begin{abstract}
Power converters with high switching frequency used to integrate renewable power sources to medium and low voltage networks are sources of emission in the supraharmonic range ( 2 to $150 \mathrm{kHz}$ ). When such converters are connected to a medium voltage (MV) network these supraharmonics propagate through the MV network and can impact network and customer equipment over a wide range. This paper evaluates an existing Swedish MV electrical network and studies the pattern of supraharmonic resonance and the propagation of supraharmonics. The MV network consists of eight feeders including a small wind farm. Simulations reveal that, the bigger the MV network, the more resonant frequencies, but also the lower the amplitude of the resonance peaks in the driving point impedance. It was also identified that for short feeders as length increases, the magnitude of the transfer impedance at supraharmonic frequency decreases. For further increment in feeder length, the magnitude increases or becomes almost constant. For very long feeders, the transfer impedance further starts decreasing. The eight feeders in the network under study are similar but show completely different impedance versus frequency characteristics. Measurements at the MV side of the wind farm show time varying emissions in the supraharmonic range during low power production. The impact of these emissions coupled with system resonance is examined.
\end{abstract}

Keywords: supraharmonics; power-system harmonics; power quality; electric power distribution; power-system modelling

\section{Introduction}

The integration of renewable energy sources, such as solar photovoltaic installations and wind turbines, to the modern electric grid using static power converters results in the emission of supraharmonics (frequency components in the range between $2 \mathrm{kHz}$ and $150 \mathrm{kHz}$ ). This range of frequency has gained significant attention, due to the increasing amount of equipment with active switching emitting supraharmonics. Lack of knowledge has been identified on aggregation, propagation and amplification of supraharmonic disturbances [1], and on research to extend the standard framework for power quality to supraharmonics [2]. Standardization organizations such as IEC (SC 77A), CENELEC (SC 205A) and IEEE are actively involved in developing standards that cover this frequency range.

Increased levels of supraharmonics have a number of adverse consequences, including malfunctioning and failure of control circuits and protection devices, impact on light intensity of LED lamps [3,4], insulation failures in cables [5], heating and accelerated aging of capacitor banks [6], heating and accelerated aging of transformers and rotating machines and loss of power line communication with smart meters [7].

A number of studies report the propagation of emission in the low voltage (LV) distribution grid [3,8-11]. A study on multiple device malfunction and noise in household appliances due to supraharmonic emissions in a public low voltage grid connected to a CNC mill with power converter is reported in [11]. Some of the emission from various LV sources may reach the MV grid, although generally the supraharmonic emission 
remain within the low-voltage installation [1,9]. Further studies have also verified that supraharmonic distortion typically decreases when propagating from a load towards the upstream network [12]. Some studies have addressed or at least mentioned resonances in LV networks at supraharmonic frequencies [13-15], but no such studies are carried out in the MV network.

Renewable energy-based power plants are a dominant source of supraharmonics in MV networks [16-18]. Grid connected solar power plants and small wind power plants are connected to the distribution network through PWM controlled power converters. They inject harmonics and supraharmonics at the point of common coupling while injecting active and reactive power to the existing network [19]. Static power converter used in variable speed control of wind turbine generators is a source of supraharmonics. Some of the different techniques adapted to improve the power quality of the grid are also sources of supraharmonics. The voltage-source converters used in FACTS devices having switching frequencies in the $\mathrm{kHz}$ range are sources of supraharmonics [20,21]. References [22,23] present measurement data identifying the sources of supraharmonics and their propagation through the MV network. The emission from sources connected to the MV network will spread through the MV network and from there to equipment connected to the LV grid. Equipment connected to the LV and MV network and components in the MV network may be damaged or otherwise negatively impacted by the supraharmonics. A detailed study on the characteristics of MV network for propagation of high frequency emissions are missing in literature and it has become a topic of growing interest within the power quality research group.

The case study of the Eagle Pass HVDC connection confirmed the failure of MV cable terminations due to a local resonance at $12.4 \mathrm{kHz}$ triggered by a supraharmonic component [5,24]. To quantify the impact of supraharmonics, indices are proposed for MV cable termination failure [25], audible noise, light flicker and tripping of the residual current breaker [26].

Understanding the origin of supraharmonics at the terminals of sensitive equipment or grid components requires information on the source (emission) of the supraharmonics and their propagation. The driving-point impedance and transfer impedances play an important role in this propagation. Resonances play an important role here as well; high harmonic levels are often associated with resonances. The measurement of supraharmonics propagation in a large MV network with multiple feeders is challenging as it requires instrument transformers with high frequency response. The other challenge in the MV network is to distinguish primary and secondary emission. Apart from this the uncertainty of the number of supraharmonic sources such as PV plant, wind plant, industrial drives to be connected to the MV network in the near future is also a major concern. Hence the study of transfer impedance of a MV network for high frequency emissions is the need of the hour. This paper studies the resonance frequency of the MV network with eight feeders using MATLAB modelling. Further it determines the transfer impedance by injecting a supraharmonic component obtained from measurements at the wind farm in one of the feeders into the MATLAB model with all eight feeders and analyzing the results.

This paper studies the propagation of supraharmonics through the MV network. Section 2 of this paper presents the supraharmonic propagation in MV network and describe the circuit under study. Section 3 describes the distributed parameter transmission line model. The analysis in Section 4 reveals the characteristics of the feeders. Real-time measurements are evaluated for supraharmonics emissions in Section 5 and a further estimation of the transfer impedance of the MV network by injecting supraharmonic emission into the MATLAB model is given in Section 6, followed by the conclusions in Section 7.

\section{Case Study: Supraharmonic Propagation in MV Network}

The harmonic distortions generated by power-electronic converters, coupled with system resonance, can cumulatively intensify when damping is insufficient and this may 
severely affect the system operation. The impedance variation and the resulting system resonance depends upon factors such as the cable length, short circuit power of the system, VAR compensator with harmonic filter and the load level in the system [22]. Reference [22] analyzed the propagation of supraharmonics in a $20 \mathrm{kV}$ electrical network with MV windpower plants and LV/MV solar-power plants. A very strong correlation was observed between supraharmonics measured at two substations $16 \mathrm{~km}$ apart. This showed the possibility of propagation of supraharmonics over long distances. The investigators also monitored voltage and current of 119th harmonic for $24 \mathrm{~h}$ and found that the levels were significantly higher between sunrise and sunset.

From the measurements, [23] concluded that solar power plants cause voltage distortion in the range between 3 and $6 \mathrm{kHz}$ as their values are above background distortion level between sunrise and sunset. Correlations in time behavior around $2.5 \mathrm{kHz}$ identified a wind power plant as the source for those frequencies.

To study the propagation of supraharmonics, an existing Swedish MV rural network (underground cabling) with eight feeders and three wind turbines in feeder B has been modelled in detail using simscape power systems toolbox in MATLAB/SIMULINK. The distributed parameter transmission line model described in Section 3 had been used for underground cables. The $16 \mathrm{MVA}, 33 \mathrm{kV} / 11 \mathrm{kV}$ transformer provides service to about 2000 low-voltage and a few medium-voltage customers. The MV network consists of eight feeders with a total length of $110 \mathrm{~km}$ and about 115 distribution transformers.

The length of the underground cables, number of transformers and number of customers in each feeder are given in Table 1. Table 2 gives details for the main $33 \mathrm{kV} / 11 \mathrm{kV}$ substation transformer.

Table 1. Feeder details.

\begin{tabular}{lccc}
\hline Feeder & Length of the Cables $\mathbf{( k m )}$ & Number of Transformers & $\begin{array}{c}\text { Number of } \\
\text { Customers }\end{array}$ \\
\hline Feeder A & 3.790 & 7 & $\begin{array}{c}\text { Domestic-115 } \\
\text { Industry-1 } \\
\text { Domestic-114 }\end{array}$ \\
Feeder B & 6.7663 & $4+3$ (Connected to Wind turbines) & Domestic-272 \\
Feeder C & 5.0894 & 7 & Domestic-313 \\
Feeder D & 29.5824 & $25+2$ (Connected to Power Station) & Domestic-332 \\
Feeder E & 4.445 & 8 & Domestic-213 \\
Feeder F & 20.0559 & 6 & Domestic-275 \\
Feeder G & 2.2002 & 33 & Domestic-345 \\
Feeder H & 39.5786 & & 18 \\
\hline
\end{tabular}

Table 2. 33 kV/11 kV Transformer details.

\begin{tabular}{lll}
\hline Power Rating & $16 \mathrm{MVA}$ & \\
\hline Impedance & $10.5 \%$ & $33 \mathrm{kV}$ \\
\hline Bus Voltage & $11 \mathrm{kV}$ & $153.6 \mathrm{MVA}$ \\
\hline Fault level & $81.5 \mathrm{MVA}$ & $7.76 \mathrm{ohms}$ \\
\hline Source Reactance & $1.68 \mathrm{ohms}$ & $1.07 \mathrm{ohms}$ \\
\hline Source Resistance & $0.15 \mathrm{ohms}$ & \\
\hline
\end{tabular}

\section{Methodology Used}

In order to determine a suitable model to study the propagation of supraharmonics, the need for distributed parameter models was estimated. The longest section in feeder $\mathrm{C}$ is about $400 \mathrm{~m}$ long. The capacitance of this section is $0.12 \mu \mathrm{F}$ and its inductance is $0.12 \mathrm{mH}$, resulting in a resonance frequency of $30 \mathrm{kHz}$. The lumped parameter model (with $50 \mathrm{~Hz}$ values for inductance and capacitance) can be used up to about one quarter of this resonance frequency, some $5-10 \mathrm{kHz}$ in this case. That means that it is necessary 
to use distributed parameter models. The Bergeron model (in time domain) is one of the options. There is also a frequency-domain model that uses a lumped-parameter PI-model with frequency dependent parameters, as for example used in [27].

A distributed parameter transmission line model has been implemented in MATLAB/SIMULINK with lumped losses based on Bergeron's traveling wave method as used in [28]. The two-port model used is shown in Figure 1.
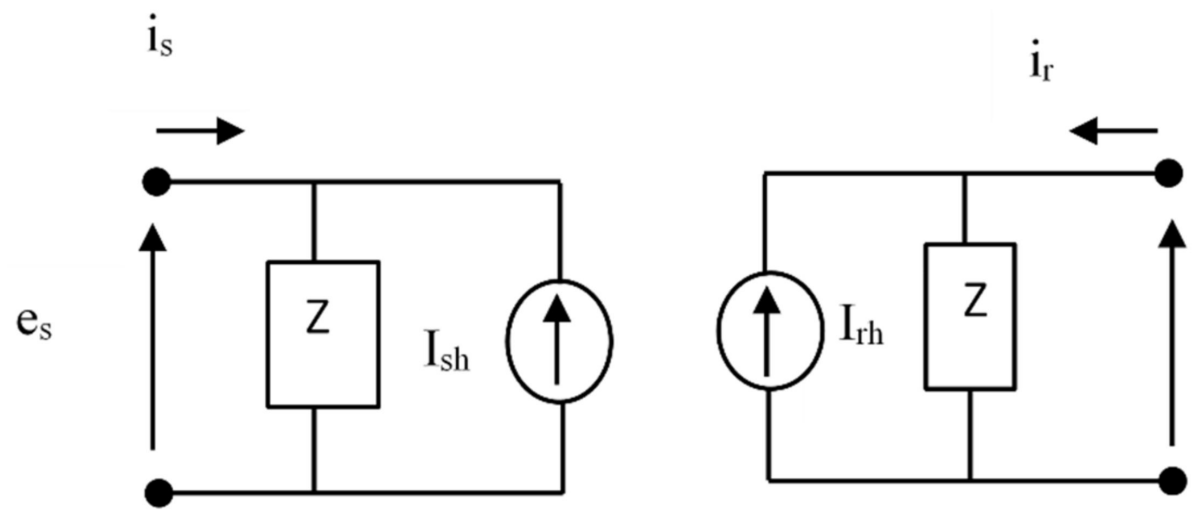

$\mathrm{e}_{\mathrm{r}}$

Figure 1. Two port network of distributed parameter transmission line model.

The surge impedance, wave propagation speed and transport delay are given by Equations (1)-(3), respectively.

$$
\begin{gathered}
Z_{c}=\sqrt{\frac{l}{c}} \\
v=1 / \sqrt{l_{c}} \\
\tau=\frac{d}{v}
\end{gathered}
$$

where $l$ and $c$ are the per unit length of inductance and capacitance, $d$ is the line length and $v$ is the propagation speed.

For a lossless line the model equations are given by (4) to (9):

$$
\begin{aligned}
& e_{r}(t)-Z_{c} i_{r}(t)=e_{S}(t-\tau)+Z_{c} i_{S}(t-\tau) \\
& e_{S}(t)-Z_{c} i_{S}(t)=e_{r}(t-\tau)+Z_{c} i_{r}(t-\tau)
\end{aligned}
$$

where

$$
\begin{gathered}
i_{s}(t)=\frac{e_{s}(t)}{Z}-I_{s h}(t) \\
i_{r}(t)=\frac{e_{r}(t)}{Z}-I_{r h}(t) \\
I_{s h}(t)=\frac{2}{Z_{c}} e_{r}(t-\tau)-I_{r h}(t-\tau) \\
I_{r h}(t)=\frac{2}{Z_{c}} e_{s}(t-\tau)-I_{s h}(t-\tau)
\end{gathered}
$$

When losses are considered, the equations for $I_{s h}$ and $I_{r h}$ are adapted by lumping one fourth of the total resistance, $\frac{R}{4}$, at both ends of the connection and $\frac{R}{2}$ in the middle of the line, where $R$ is the total resistance of the cable or line connection. At higher frequencies, where the penetration depth is controlled by the skin effect, both the resistance and reactance increase with the square root of frequency. Considering this relationship, the impedance with skin effect is calculated [29].

The current sources $I_{s h}$ and $I_{r h}$, in Figure 1, are then computed as follows: 


$$
\begin{aligned}
& I_{s h}(t)=\left(\frac{1+h}{2}\right)\left(\frac{1+h}{Z} e_{r}(t-\tau)-h I_{r h}(t-\tau)\right)+\left(\frac{1+h}{2}\right)\left(\frac{1+h}{Z} e_{S}(t-\tau)-h I_{s h}(t-\tau)\right) \\
& I_{r h}(t)=\left(\frac{1+h}{2}\right)\left(\frac{1+h}{Z} e_{s}(t-\tau)-h I_{s h}(t-\tau)\right)+\left(\frac{1+h}{2}\right)\left(\frac{1+h}{Z} e_{r}(t-\tau)-h I_{r h}(t-\tau)\right)
\end{aligned}
$$

where

$$
\begin{aligned}
Z & =\sqrt{\frac{l}{c}}+\frac{r}{4} \\
h & =\frac{\sqrt{\frac{l}{c}}-\frac{r}{4}}{\sqrt{\frac{l}{c}}+\frac{r}{4}} \\
\tau & =d \sqrt{l c}
\end{aligned}
$$

where $r, l, c$ are the resistance, inductance and capacitance per unit length, respectively, and line length is represented by $d$. For a lossless line, $r=0, h=1$, and $Z=\sqrt{\frac{l}{c}}$.

\section{Results and Analysis}

\subsection{Feeder C First Estimation}

An estimation of the resonance frequency for feeder $\mathrm{C}$ in Figure 2 was made. The total cable length of feeder C is $5.0894 \mathrm{~km}$. From Tables 2 and A1 in Appendix A the total capacitance of feeder $\mathrm{C}$ is $2.5208 \mu \mathrm{F}$.

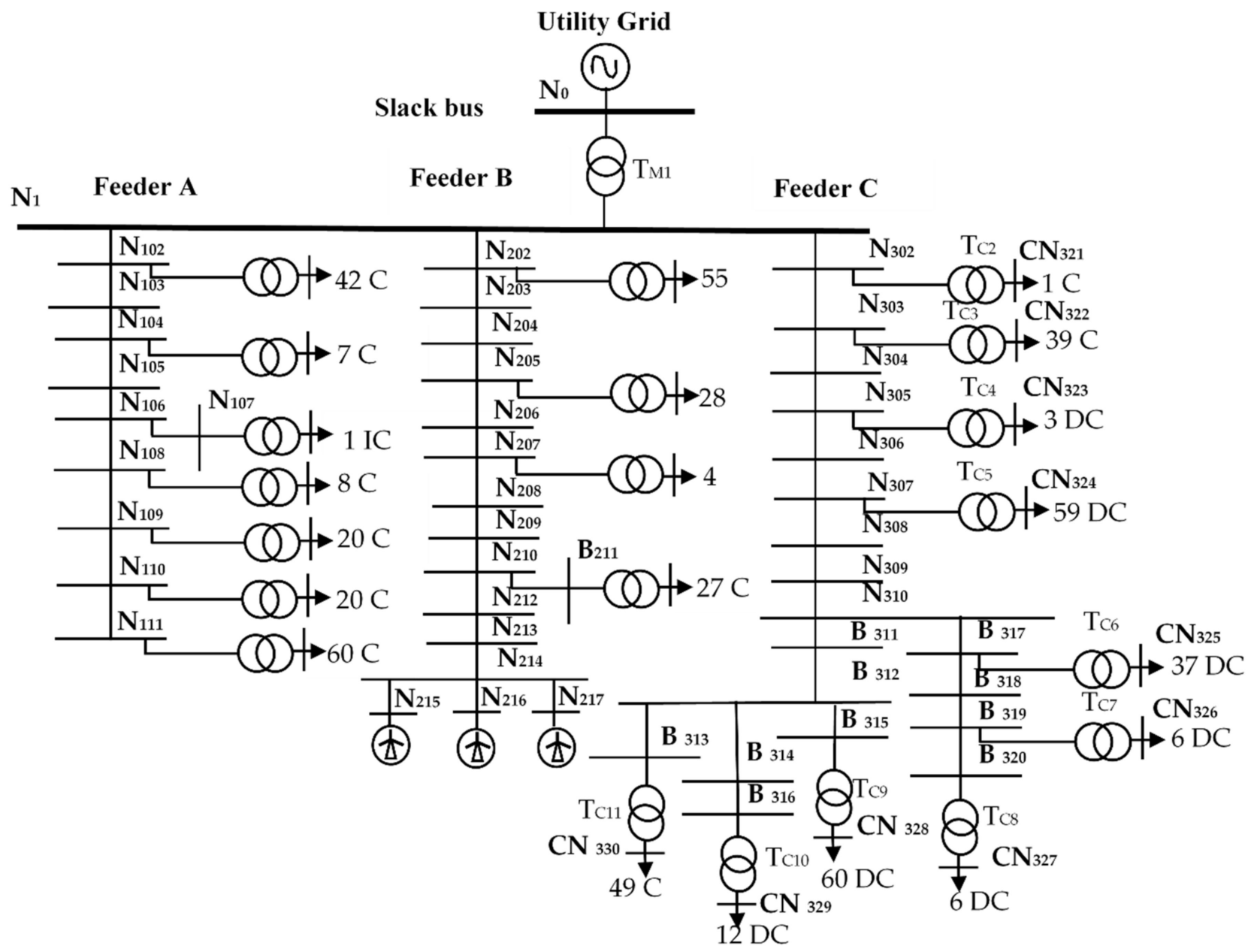

Figure 2. Single line diagram of feeder A, B and C with 272 customers. 
Considering only the source impedance at $33 \mathrm{kV}$ and the $33 \mathrm{kV} / 11 \mathrm{kV}$ transformer impedance for the inductance, the first resonance frequency is given by,

$$
f_{\text {res }}=\frac{1}{2 \pi \sqrt{2.5208 \mu \mathrm{F} \cdot 13.04 \mathrm{mH}}}=871.17 \mathrm{~Hz}
$$

The characteristic impedance of this first resonance frequency is $71.9 \Omega$. This corresponds, at $10 \mathrm{kV}$, to a load of $1.4 \mathrm{MW}$ (assuming that resistance at $850 \mathrm{~Hz}$ is the same as at $50 \mathrm{~Hz}$ for a rough estimation). This characteristic impedance is the impedance (load) at which the resonance circuit is "critically damped", i.e., when the impedance is much higher (load much lower) there is not much damping of the resonance.

The cable parameters such as operational impedance $\left(Z_{o p}\right)$, inductance per unit length ( $l$ ) and capacitance per unit length (c) of feeder C, obtained from [30], are given in Table A1 in Appendix A. Table 3 represents the type and length of cable used between the nodes. The transformer parameters of Figure 2 are given in Table A2 in Appendix A.

Table 3. Cable length of the medium voltage network.

\begin{tabular}{cccccccc}
\hline Node 1 & Node 2 & $\begin{array}{c}\text { Type } \\
\text { Cable/Transformer }\end{array}$ & $\begin{array}{c}\text { Length } \\
(\mathbf{k m})\end{array}$ & Node 1 & Node 2 & $\begin{array}{c}\text { Type } \\
\text { Cable/Transformer }\end{array}$ & $\begin{array}{c}\text { Length } \\
(\mathbf{k m})\end{array}$ \\
\hline $\mathrm{N}_{1}$ & $\mathrm{~N}_{0}$ & $\mathrm{~T}_{\mathrm{M} 1}$ & 0.0000 & $\mathrm{~N}_{310}$ & $\mathrm{~N}_{317}$ & $\mathrm{C}_{6}$ & 0.5076 \\
$\mathrm{~N}_{1}$ & $\mathrm{~N}_{302}$ & $\mathrm{C}_{1}$ & 0.6442 & $\mathrm{~N}_{311}$ & $\mathrm{~N}_{312}$ & $\mathrm{C}_{1}$ & 0.3716 \\
$\mathrm{~N}_{302}$ & $\mathrm{~N}_{303}$ & $\mathrm{C}_{1}$ & 0.3147 & $\mathrm{~N}_{312}$ & $\mathrm{~N}_{313}$ & $\mathrm{C}_{1}$ & 0.2949 \\
$\mathrm{~N}_{302}$ & $\mathrm{CN}_{321}$ & $\mathrm{~T}_{\mathrm{C} 2}$ & 0.0000 & $\mathrm{~N}_{312}$ & $\mathrm{~N}_{314}$ & $\mathrm{C}_{4}$ & 0.2249 \\
$\mathrm{~N}_{303}$ & $\mathrm{~N}_{304}$ & $\mathrm{C}_{1}$ & 0.4873 & $\mathrm{~N}_{312}$ & $\mathrm{~N}_{315}$ & $\mathrm{C}_{1}$ & 0.3542 \\
$\mathrm{~N}_{303}$ & $\mathrm{CN}_{322}$ & $\mathrm{~T}_{\mathrm{C} 3}$ & 0.0000 & $\mathrm{~N}_{313}$ & $\mathrm{CN}_{330}$ & $\mathrm{~T}_{\mathrm{C} 11}$ & 0.0000 \\
$\mathrm{~N}_{304}$ & $\mathrm{~N}_{305}$ & $\mathrm{C}_{2}$ & 0.0198 & $\mathrm{~N}_{314}$ & $\mathrm{~N}_{316}$ & $\mathrm{C}_{5}$ & 0.0028 \\
$\mathrm{~N}_{305}$ & $\mathrm{~N}_{306}$ & $\mathrm{C}_{2}$ & 0.0236 & $\mathrm{~N}_{315}$ & $\mathrm{CN}_{328}$ & $\mathrm{~T}_{\mathrm{C} 9}$ & 0.0000 \\
$\mathrm{~N}_{305}$ & $\mathrm{CN}_{323}$ & $\mathrm{~T}_{\mathrm{C} 4}$ & 0.0000 & $\mathrm{~N}_{316}$ & $\mathrm{CN}_{29}$ & $\mathrm{~T}_{\mathrm{C} 10}$ & 0.0000 \\
$\mathrm{~N}_{306}$ & $\mathrm{~N}_{307}$ & $\mathrm{C}_{1}$ & 0.336 & $\mathrm{~N}_{317}$ & $\mathrm{~N}_{318}$ & $\mathrm{C}_{6}$ & 0.0179 \\
$\mathrm{~N}_{307}$ & $\mathrm{~N}_{308}$ & $\mathrm{C}_{1}$ & 0.3143 & $\mathrm{~N}_{317}$ & $\mathrm{CN}_{325}$ & $\mathrm{~T}_{\mathrm{C} 6}$ & 0.0000 \\
$\mathrm{~N}_{307}$ & $\mathrm{CN}_{324}$ & $\mathrm{~T}_{\mathrm{C} 5}$ & 0.0000 & $\mathrm{~N}_{318}$ & $\mathrm{~N}_{319}$ & $\mathrm{C}_{7}$ & 0.4078 \\
$\mathrm{~N}_{308}$ & $\mathrm{~N}_{309}$ & $\mathrm{C}_{1}$ & 0.2710 & $\mathrm{~N}_{319}$ & $\mathrm{~N}_{320}$ & $\mathrm{C}_{8}$ & 0.3576 \\
$\mathrm{~N}_{309}$ & $\mathrm{~N}_{310}$ & $\mathrm{C}_{3}$ & 0.0706 & $\mathrm{~N}_{319}$ & $\mathrm{CN}_{326}$ & $\mathrm{~T}_{7}$ & 0.0000 \\
$\mathrm{~N}_{310}$ & $\mathrm{~N}_{311}$ & $\mathrm{C}_{3}$ & 0.0686 & $\mathrm{~N}_{320}$ & $\mathrm{CN}_{327}$ & $\mathrm{~T}_{8}$ & 0.0000 \\
\hline
\end{tabular}

\subsubsection{Feeder C Driving Point Impedance}

The driving point impedance calculated at the nodes is obtained from the transfer function of the voltage output to the injected current input of the state space model. The node 1 impedance of the network shown in Figure 2 without feeder A and B, with all cables and transformers of feeder $\mathrm{C}$, without any load connected to the distribution transformers has a resonance at $866 \mathrm{~Hz}$, which corresponds well with the $871 \mathrm{~Hz}$ value obtained from the estimation. Though the first peak is below the supraharmonics range, it is relevant for other studies. It is included here for completeness. The medium voltage network also has a number of small resonance peaks between 2 and $150 \mathrm{kHz}$, as shown in Figure 3 .

\subsubsection{Impact of Cable Length}

The total length of the cables of the system under study was $5.09 \mathrm{~km}$. The impedance versus frequency of the system, with skin effect included, has been calculated when the length is increased to 1.5 and 2 times the original length. The results are shown in Figure 4. The magnitude of the impedance at the resonance frequency decreases with increase in cable length. Additionally, multiple resonances appear as the cable length increases; these are also shifted towards the lower frequency as shown in Figure 4. 


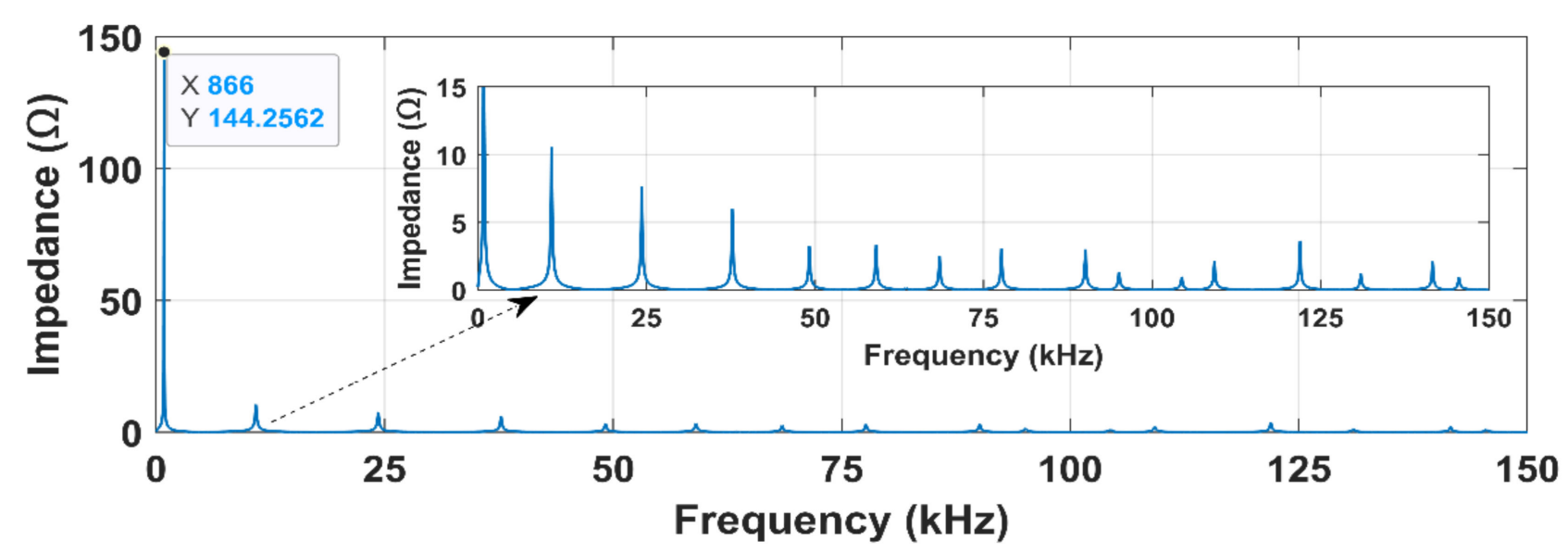

Figure 3. Frequency response without load.

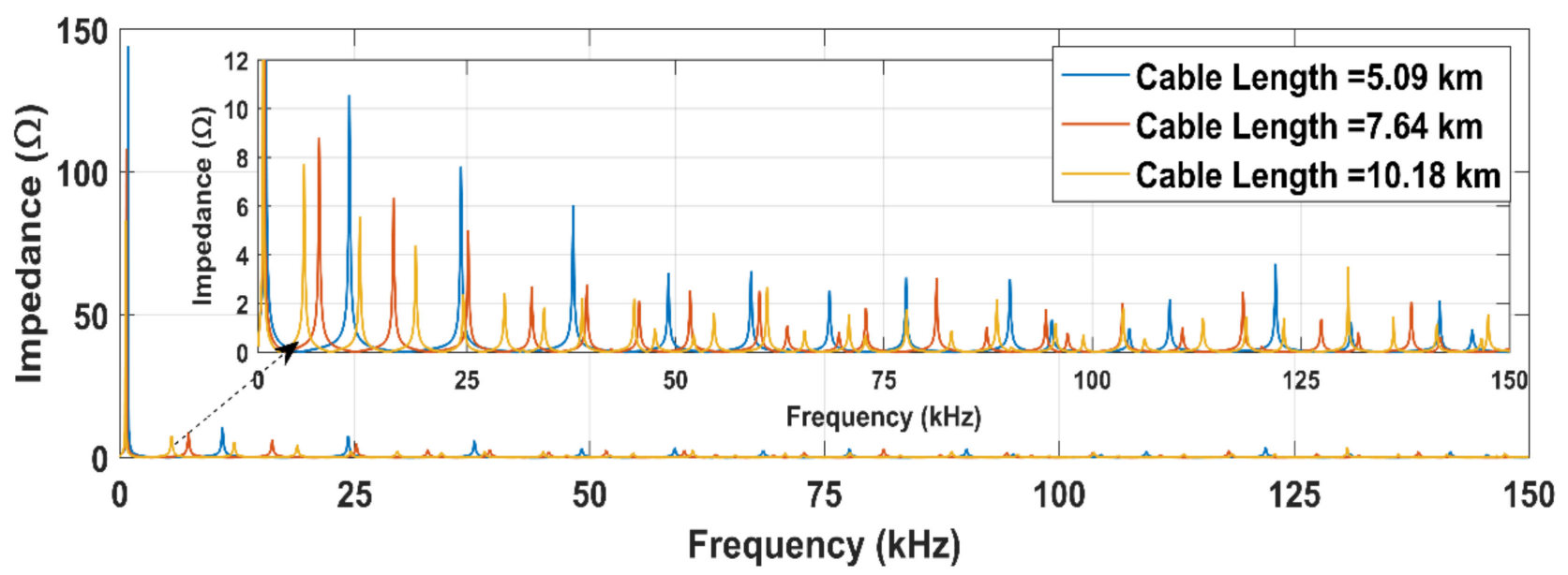

Figure 4. Frequency response at different cable length.

\subsubsection{Impact of Load Impedance}

Considering maximum load values of $3.5 \mathrm{~kW}$ and $0.5 \mathrm{kVAR}$ per LV customer obtained in consultation with field experts, the input impedance of the network with original length was again determined and the resulting resonances at $1255 \mathrm{~Hz}$ and $11 \mathrm{kHz}$ are shown in Figure 5. It was shown earlier that the characteristic impedance of the lowest-frequency resonance corresponds to a load of $1400 \mathrm{~kW}$. The load considered here is 272 times $3.5 \mathrm{~kW}$ or about $1000 \mathrm{~kW}$, which is somewhat below the characteristic load. The impedance at the first resonance peak drops from over $144 \Omega$ in Figure 3 to around $4 \Omega$ in Figure 5. On the other hand, load has less impact on the supraharmonic frequencies.

\subsection{Feeder $A, B$ and $C$ Characteristics}

In the previous section the characteristics of feeder $C$ were analyzed in detail. In this section along with feeder C, feeder A and B are also connected as shown in Figure 3 and the characteristics of this combined configuration are studied. Magnitude of transfer impedance obtained using fast Fourier transform (FFT) analysis at the distribution transformer MV side by injecting a harmonic current at node 1 and node 214 is presented in Table 4. 


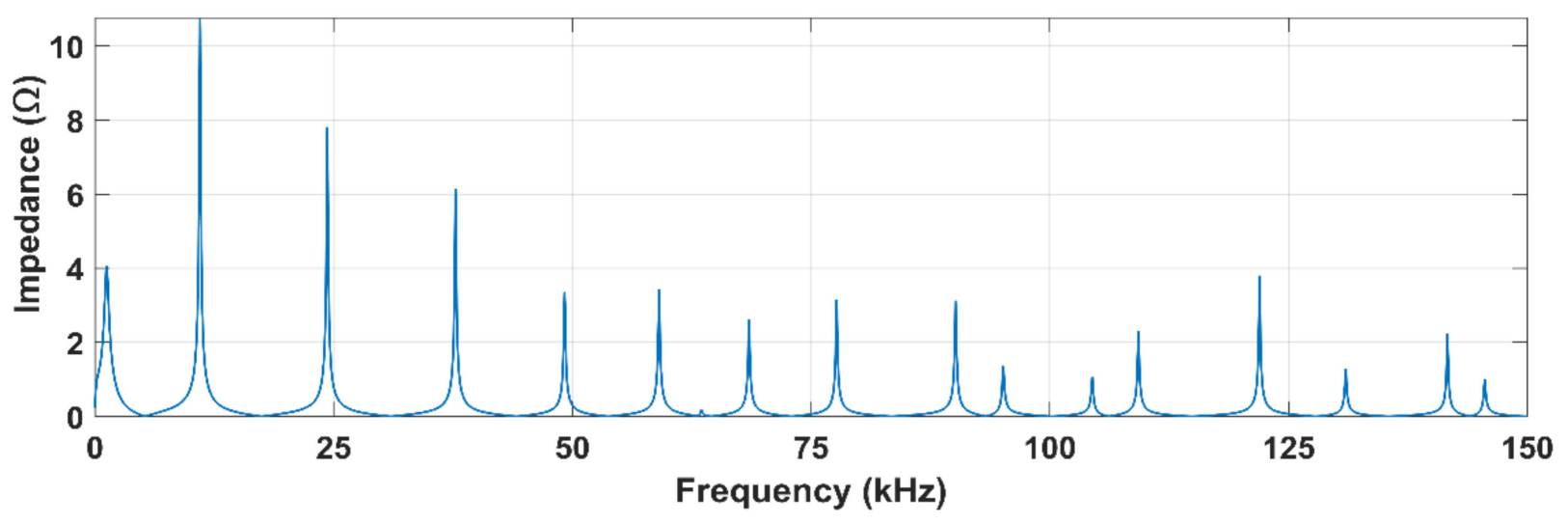

Figure 5. Frequency response with load.

Table 4. Magnitude of transfer impedance obtained using FFT analysis.

\begin{tabular}{|c|c|c|c|c|}
\hline \multirow[t]{3}{*}{$\begin{array}{l}\text { Main Node } \\
\text { (Point of } \\
\text { Measurement) }\end{array}$} & \multirow{3}{*}{$\begin{array}{l}\text { Distance of Main } \\
\text { Node from Point of } \\
\text { Injection (Node 1) } \\
(\mathbf{k m})\end{array}$} & \multirow{3}{*}{$\begin{array}{l}\text { Distance of Main } \\
\text { Node from Point of } \\
\text { Injection } \\
\text { (Node 214) } \\
\text { (km) }\end{array}$} & $\begin{array}{c}\text { Magnitude of } 1 \mathrm{~A}, \\
12.8 \mathrm{kHz} \\
\text { Harmonic Current } \\
\text { Injected at Node } 1\end{array}$ & $\begin{array}{c}\text { Magnitude of } 1 \mathrm{~A}, \\
12.8 \mathrm{kHz} \\
\text { Harmonic Current } \\
\text { Injected at Node } 214\end{array}$ \\
\hline & & & \multicolumn{2}{|c|}{ Transfer Impedance } \\
\hline & & & $\Omega$ & $\mathrm{m} \Omega$ \\
\hline \multicolumn{5}{|c|}{ Feeder A } \\
\hline 102 & 0.368 & 4.82861 & 1.94 & 8.6 \\
\hline 104 & 1.0931 & 5.55371 & 0.31 & 1.3 \\
\hline 107 & 1.4166 & 5.87721 & 0.29 & 1.27 \\
\hline 108 & 1.5804 & 6.04101 & 0.93 & 4.08 \\
\hline 109 & 2.2534 & 6.71401 & 3.03 & 13.52 \\
\hline 110 & 3.156 & 7.61631 & 4.87 & 21.72 \\
\hline 111 & 3.6892 & 8.14981 & 5.19 & 22.94 \\
\hline \multicolumn{5}{|c|}{ Feeder B } \\
\hline 202 & 0.43521 & 4.0253 & 2.2 & 9.82 \\
\hline 205 & 1.19811 & 3.2624 & 0.8 & 3.6 \\
\hline 207 & 1.58641 & 2.8741 & 0.0014 & $3.5 \times 10^{-7}$ \\
\hline 211 & 3.63501 & 1.2537 & $7.7 \times 10^{-7}$ & $1.77 \times 10^{-7}$ \\
\hline \multicolumn{5}{|c|}{ Feeder C } \\
\hline 302 & 0.6442 & 5.10471 & 2.72 & 12.03 \\
\hline 303 & 0.9589 & 5.41941 & 2.47 & 10.8 \\
\hline 305 & 1.466 & 5.92651 & 1.61 & 7.1 \\
\hline 307 & 1.8256 & 6.28611 & 0.77 & 3.3 \\
\hline 313 & 3.2166 & 7.67711 & 1.69 & 7.3 \\
\hline 315 & 3.2759 & 7.73641 & 1.61 & 7.31 \\
\hline 316 & 3.1494 & 7.60991 & 1.47 & 7.1 \\
\hline 317 & 2.9891 & 7.44961 & 1.72 & 8.46 \\
\hline 319 & 3.4148 & 7.87531 & 1.79 & 8.69 \\
\hline 320 & 3.7724 & 8.23291 & 1.66 & 7.6 \\
\hline
\end{tabular}

Table 4 shows that the magnitude of transfer impedance initially decreases and further increases with increment in length and, in the case of Feeder $C$, it becomes almost constant towards the end of the feeder. Feeder B, with three wind turbines connected close to the node 214, shows a decreasing transfer impedance pattern.

The magnification of harmonic voltage at node 109,110 and 111 towards the end of feeder $\mathrm{A}$ is noticeable. For a $1 \mathrm{~A}, 12.8 \mathrm{kHz}$ (chosen based on the maximum resonance peak obtained using the combination of feeder A, B and C) supraharmonic current injection 
at node 1 , node 109 generates $3 \mathrm{~V}$, node 110 generates $4 \mathrm{~V}$ and Node 111 generates $5 \mathrm{~V}$ corresponding to a $10 \mathrm{kV}$ system. The driving point impedance versus frequency at the MV side of the distribution transformer for feeder A, B and C is shown in Figure 6.

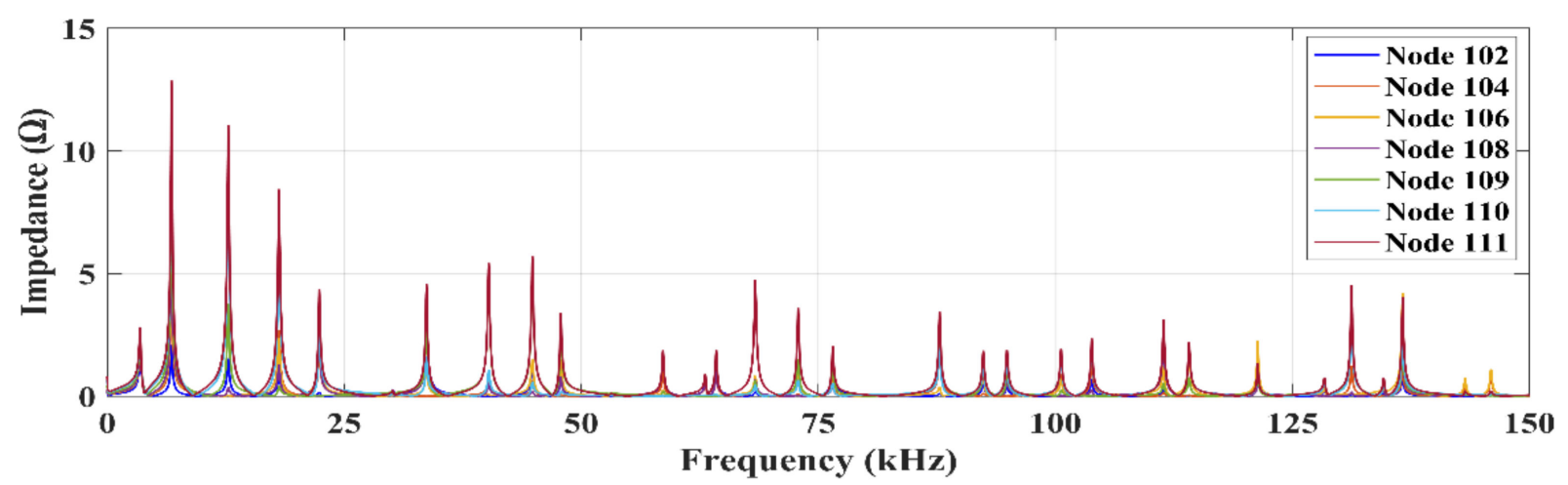

(a)

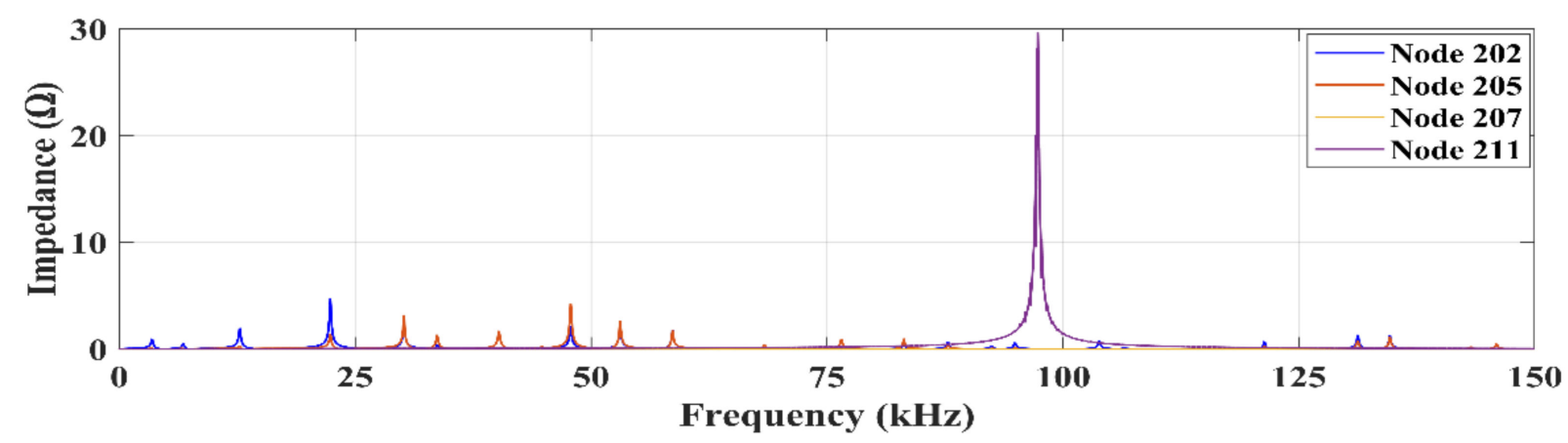

(b)

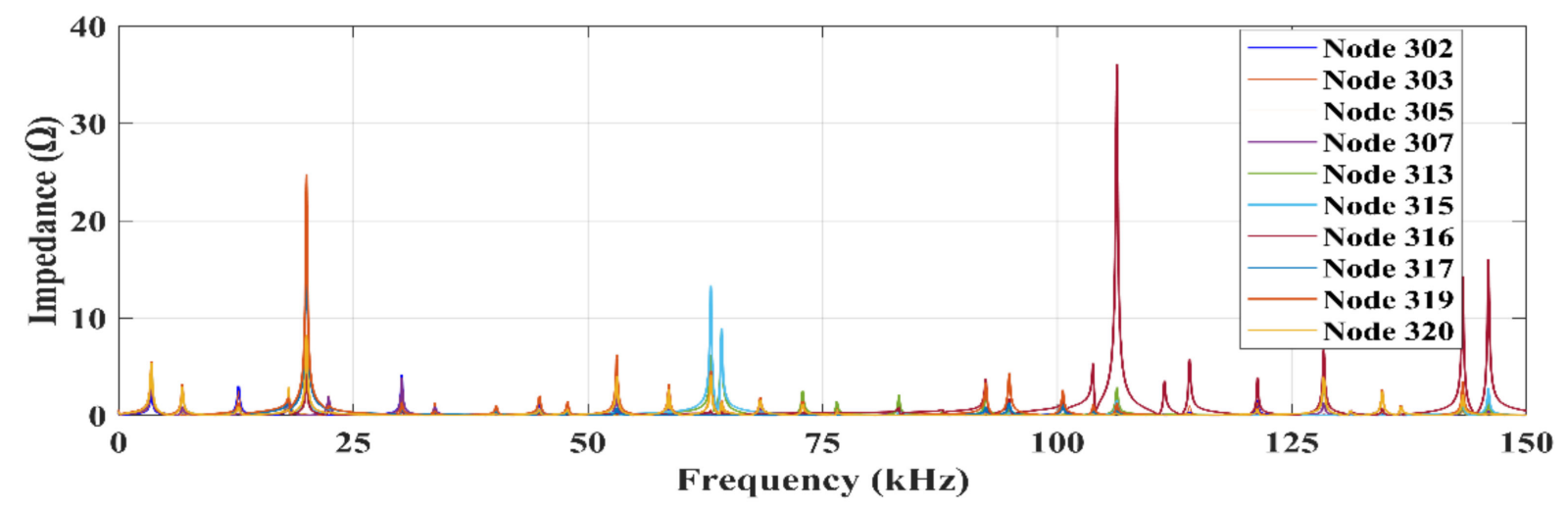

(c)

Figure 6. Driving point impedance of test network at medium voltage (MV) side of distribution transformer (a) feeder A, (b) feeder B and (c) feeder C.

It is noticeable that the three feeders are rather similar in length and number of customers, but show big differences in the driving-point impedance.

\subsection{Feeders $A, B, C, D, E, F, G$ and $H$ Characteristics}

In order to determine the input impedance of an MV network with eight feeders, four different configurations are studied by gradually increasing the number of feeders. Initially the input impedance of feeder C followed by feeder A, B and C followed by feeder A, B, $\mathrm{C}$ and $\mathrm{D}$ and finally all eight feeders are compared. All eight feeder details are given in 
Table 1 . The input impedance obtained by a frequency scan at node 1 with four different feeder configurations with skin effect is shown in Figure 7.

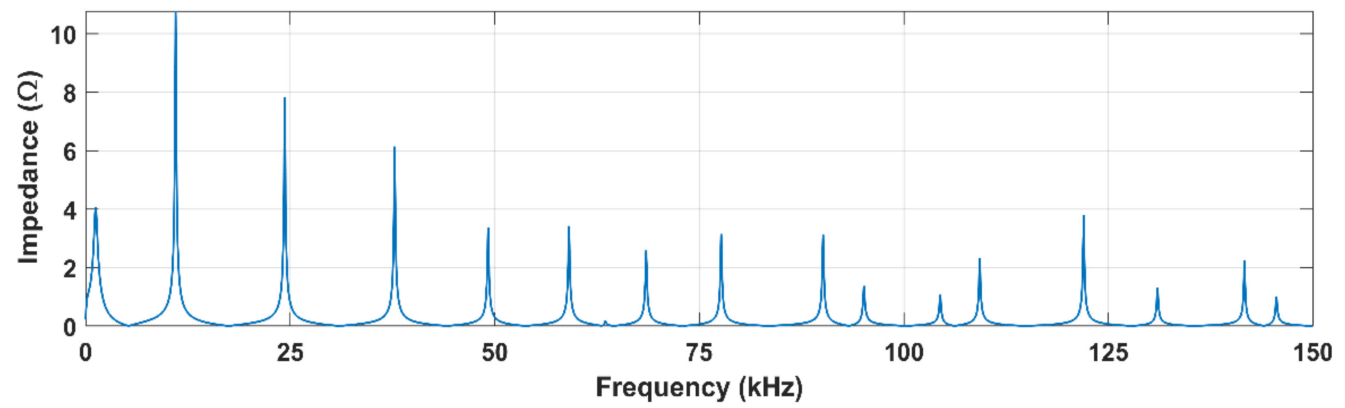

(a)

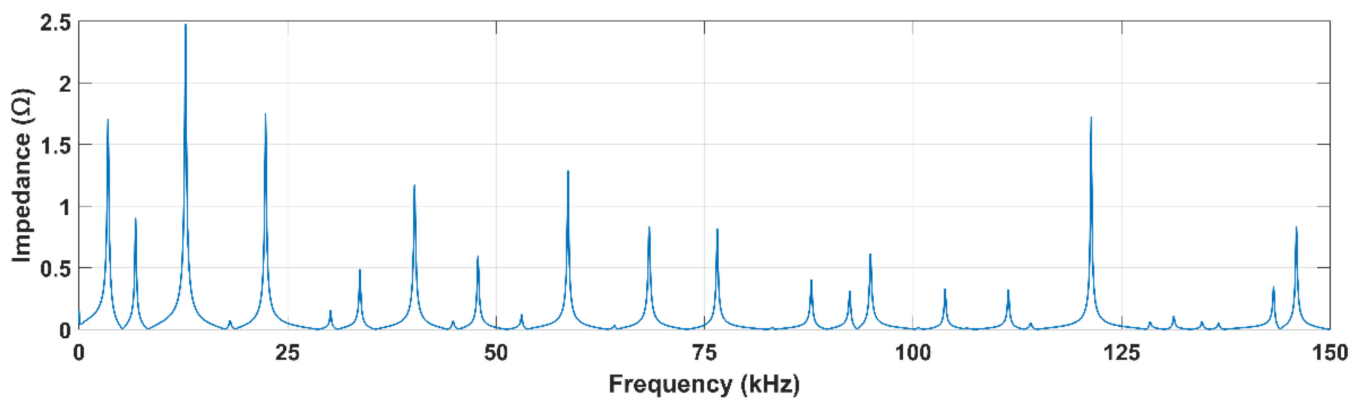

(b)

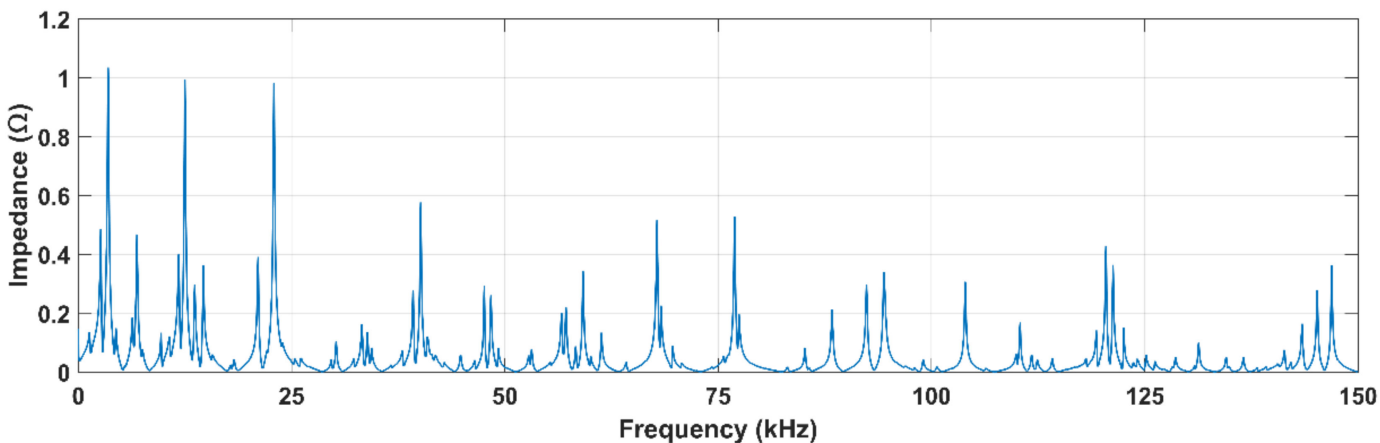

(c)

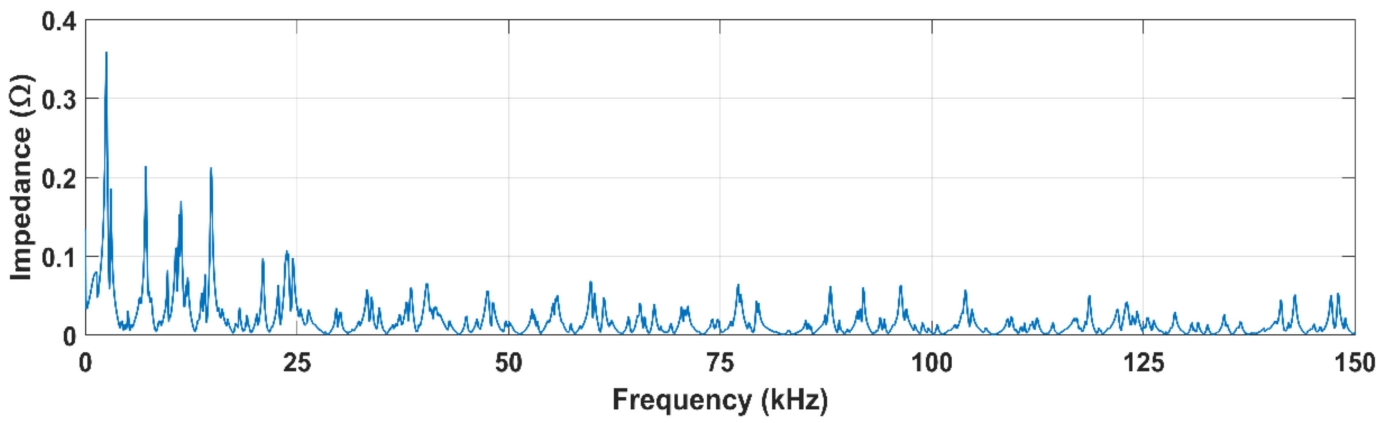

(d)

Figure 7. MV network impedance at node 1 (a) feeder C, (b) feeder A, B and C, (c) feeder A, B, C and D and (d) feeder A, B, C, D, E, F, G and H. Note the difference in vertical scale between.

The system impedance of feeder $\mathrm{C}$ is characterized by succession of parallel resonances over the range 0 to $150 \mathrm{kHz}$. As the number of feeders is increased, the magnitude of impedance decreases, and the number of resonance peaks increases as shown in Figure $7 \mathrm{c}, \mathrm{d}$. 


\section{Supraharmonic Measurement at Feeder B}

The power quality monitoring of a MV/LV network with $33 \mathrm{kV} / 11 \mathrm{kV}$ transformer connected to eight different distribution feeders has been performed. Feeder $\mathrm{B}$ is connected to three wind turbines which cause the injection of supraharmonics into the MV network. A Hioki 8855 power quality monitor was used to acquire measurement data from the LV side of a $700 \mathrm{kVA}$ transformer connecting a wind turbine. Pearson 411 current transformer with frequency resolution ranging from $1 \mathrm{~Hz}$ to $20 \mathrm{MHz}$ was used. Different samples of data were acquired for $10 \mathrm{~s}$ at $5 \mathrm{~min}$ intervals with a sampling frequency of $500 \mathrm{kHz}$. The spectrum of voltage and current waveforms was obtained for $200 \mathrm{~ms}$ (10 cycles) using DFT with rectangular window. Hence, the frequency resolution of resulting spectra is $5 \mathrm{~Hz}$. During normal operation of the converter, the switching frequency is $10 \mathrm{kHz}$, as shown in Figure 8.
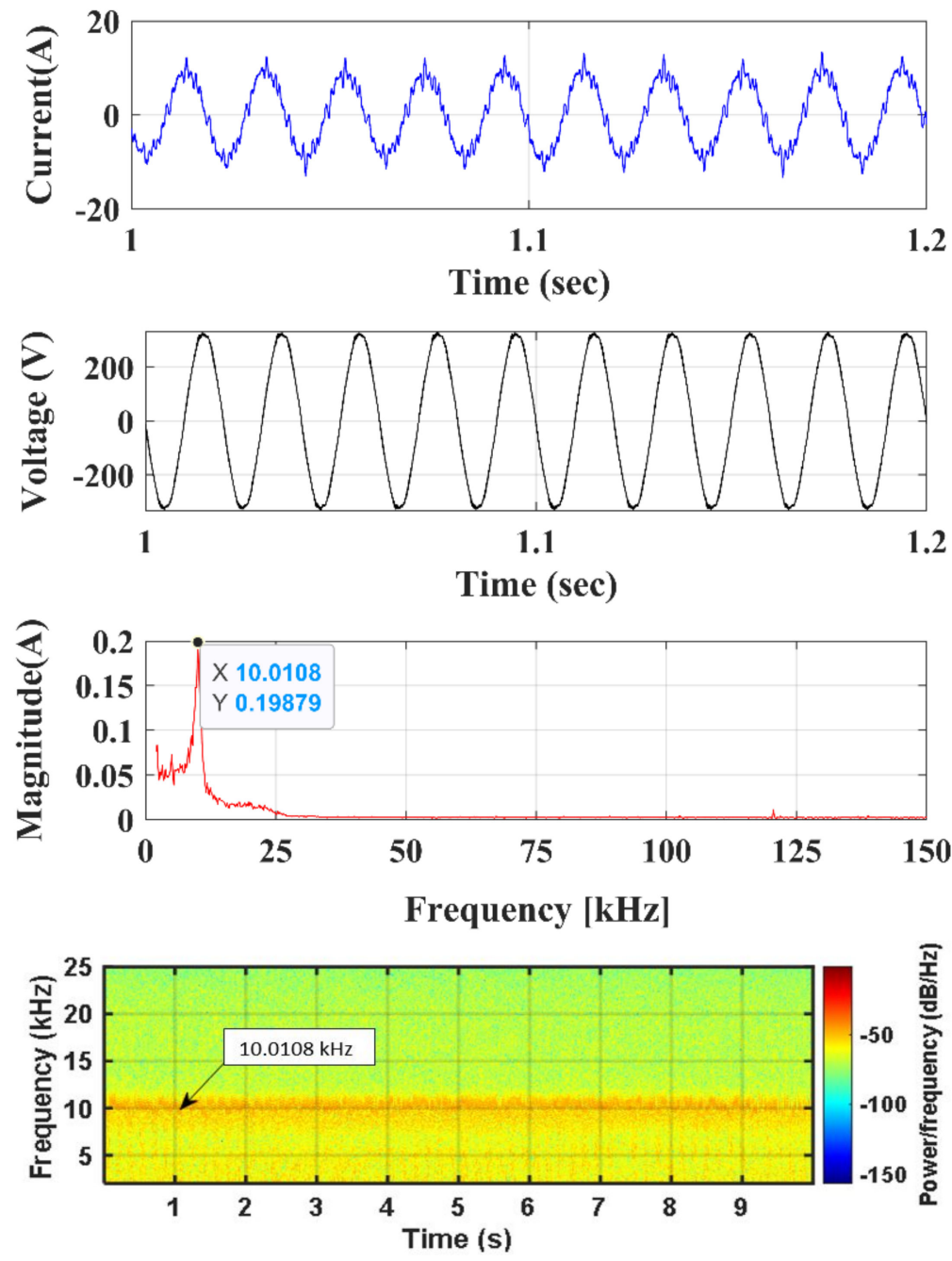

Figure 8. Transformer MV side current and voltage waveforms along with its spectrum with dominant emission at $10 \mathrm{kHz}$ at PCC of wind turbines of feeder B.

To reduce the mechanical stress and increase the energy capture, a robust control scheme is used to control doubly fed induction generator (DFIG) based wind turbines [31,32]. During low power extraction, a time varying emission due to the variation of the switching frequency of the wind turbine at different operating modes of the converter was observed. Switching frequencies were ranging from 7 to $10 \mathrm{kHz}$. Switching frequencies of $7.6,8$ and $9 \mathrm{kHz}$ during low active power generation are shown in Figure 9. 


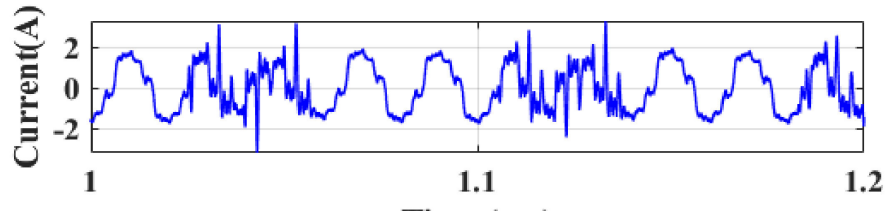

Time (sec)
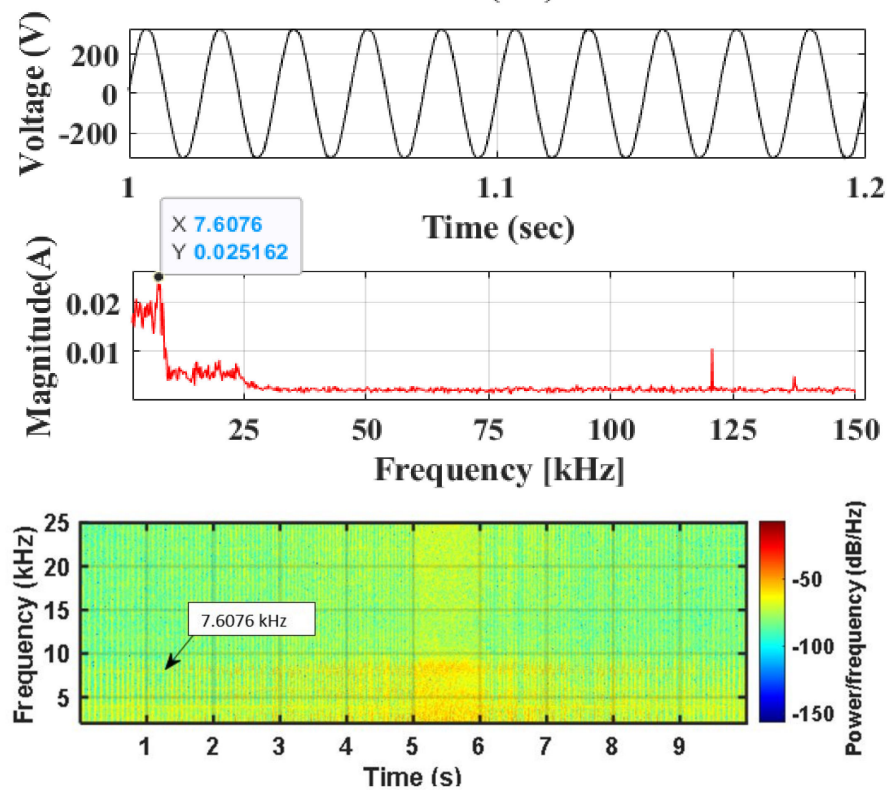

(a)
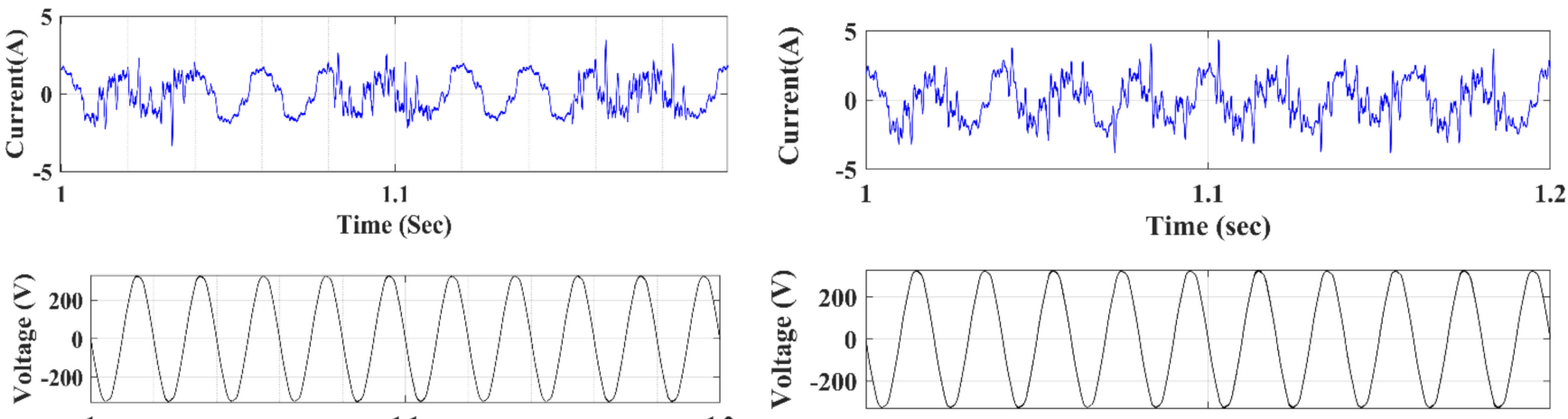

Time (Sec)

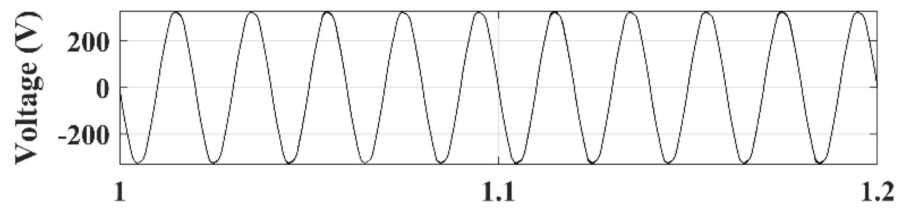

Time (Sec)
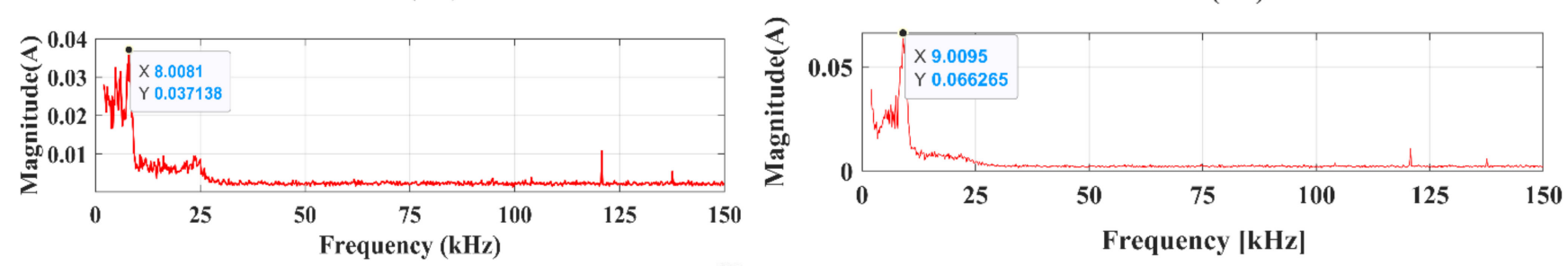

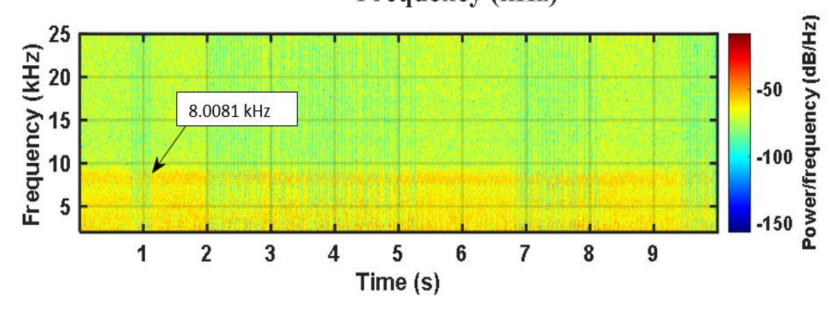

(b)

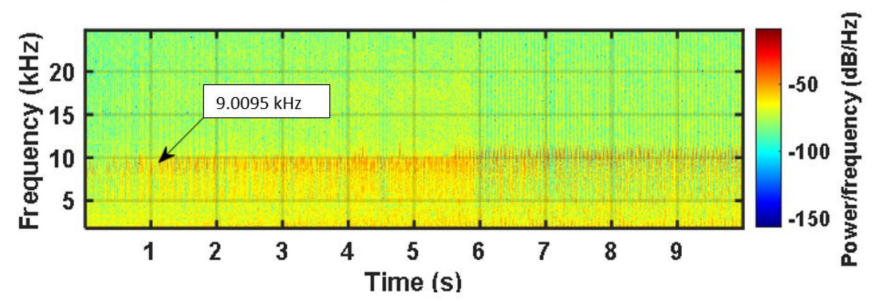

(c)

Figure 9. Transformer MV side current and voltage waveforms along with its dominant emission at (a) 7.6, (b) 8 and (c) $9 \mathrm{kHz}$ at PCC of wind turbines of feeder B. 


\section{Transfer Impedance Estimation}

The supraharmonic emissions of $10 \mathrm{kHz}, 0.2 \mathrm{~A}, 9 \mathrm{kHz}, 0.066 \mathrm{~A}, 8 \mathrm{kHz}, 0.037 \mathrm{~A}$ and $7.6 \mathrm{kHz}, 0.025 \mathrm{~A}$, observed in the measurements, injected by the wind turbines at PCC, have been used for further analysis. These supraharmonic currents were injected into the MV side of the wind turbine transformer at node 214 (point of connection of wind turbines) of the developed MATLAB model with all eight feeders. The transfer impedance is obtained as a ratio of the voltages developed at selected nodes of different feeders to the injected supraharmonic current. The transfer impedance measurement as a function of frequency is obtained at the MV side of selected distribution transformers (selected based on the distance from the main $33 \mathrm{kV} / 11 \mathrm{kV}$ transformer) of all eight feeders as shown in Figure 10. It is noticed that the transfer impedance value decreases for short feeders and for further increment in length of the feeder the transfer impedance increases. For very long feeders it again starts decreasing towards the end of the feeder.

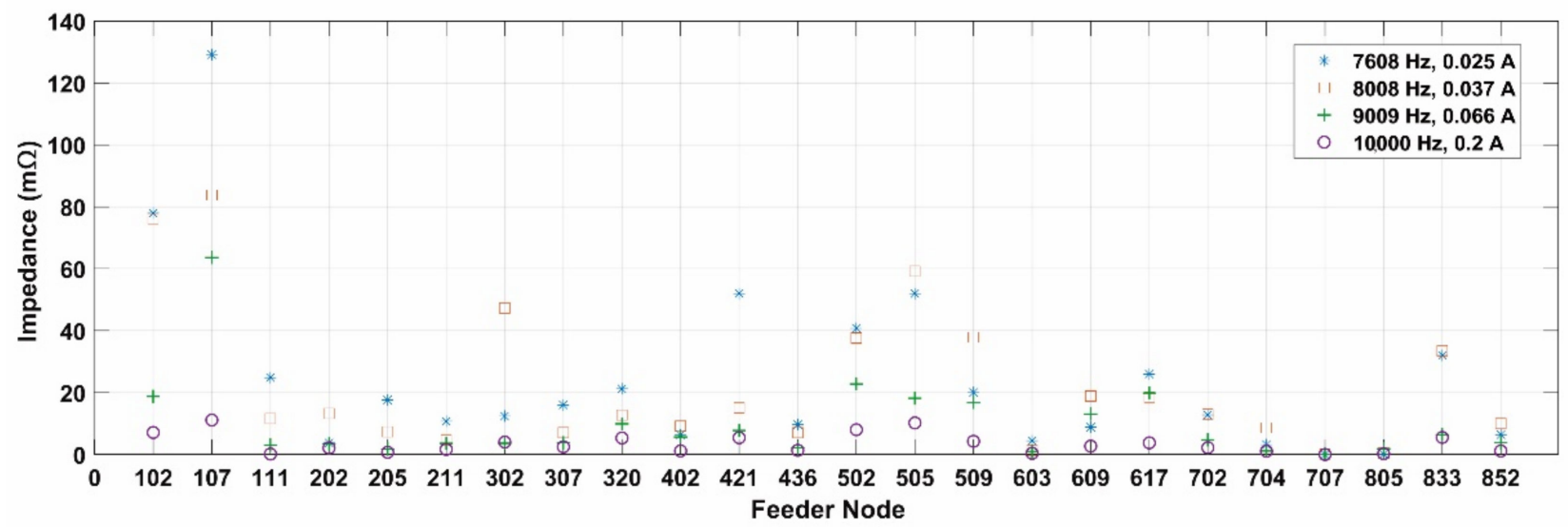

Figure 10. Transfer Impedance at different nodes of the MV network for supraharmonic current injection.

To determine how severe these impedance values are, let us consider that the $700 \mathrm{kVA}$ wind turbine in feeder $\mathrm{B}$ injects $1 \%$ supraharmonic current at the resonance frequency. The rating, $700 \mathrm{kVA}, 10 \mathrm{kV}$, corresponds to $40 \mathrm{~A}$ rated current; hence $1 \%$ supraharmonic current is $0.4 \mathrm{~A}$. Assuming a transfer impedance of $130 \mathrm{~m} \Omega$ at node 107 of feeder $\mathrm{A}, 0.4$ A gives a voltage of $0.052 \mathrm{~V}$, which is a very small value of the nominal phase-to-neutral voltage. Hence it can be concluded that the transfer impedance values are very small in the medium voltage network with all eight feeders under study and it does not create much impact on the grid. On the other hand, with three feeder configuration in Section 4.2 the node 111 was capable of generating $5 \mathrm{~V}$ under the influence of supraharmonic current of $1 \mathrm{~A}, 12.8 \mathrm{kHz}$.

The $5 \mathrm{~V}$ generated by the supraharmonics current of $1 \mathrm{~A}$ is plotted with respect to the EN50160 standard voltage limits for frequency range $95 \mathrm{kHz}$ upto $148.5 \mathrm{kHz}$ used in public $\mathrm{LV}$ and MV network [2]. Voltage level in \% for $5 \mathrm{~V}$ corresponding to $10 \mathrm{kV}$ is $0.05 \%$ which is within the standards as shown in Figure 11. If aggregation of supraharmonics generated by multiple devices get amplified by resonance and generate $50 \mathrm{~V}$ it would cross the EN50160 standard. The limits according to EN50065 and IEC 61000-3-8 is only 2\% of nominal voltage for the frequency range between 3 and $9 \mathrm{kHz}$ [2]. In this case an aggregation of $20 \mathrm{~V}$ in the $10 \mathrm{kV}$ network will cross the IEC standard limit. Hence advance study on different network configurations with large numbers of power converters and their aggregation in the supraharmonics range are essential. This would help the standardization committee to fix the new equipment's emission limit in the supraharmonics range during their testing. It should be noted that all limits in this frequency range was fixed based on power line communication apparatus, hence the limits need to be redefined based on the modern power system requirements. 


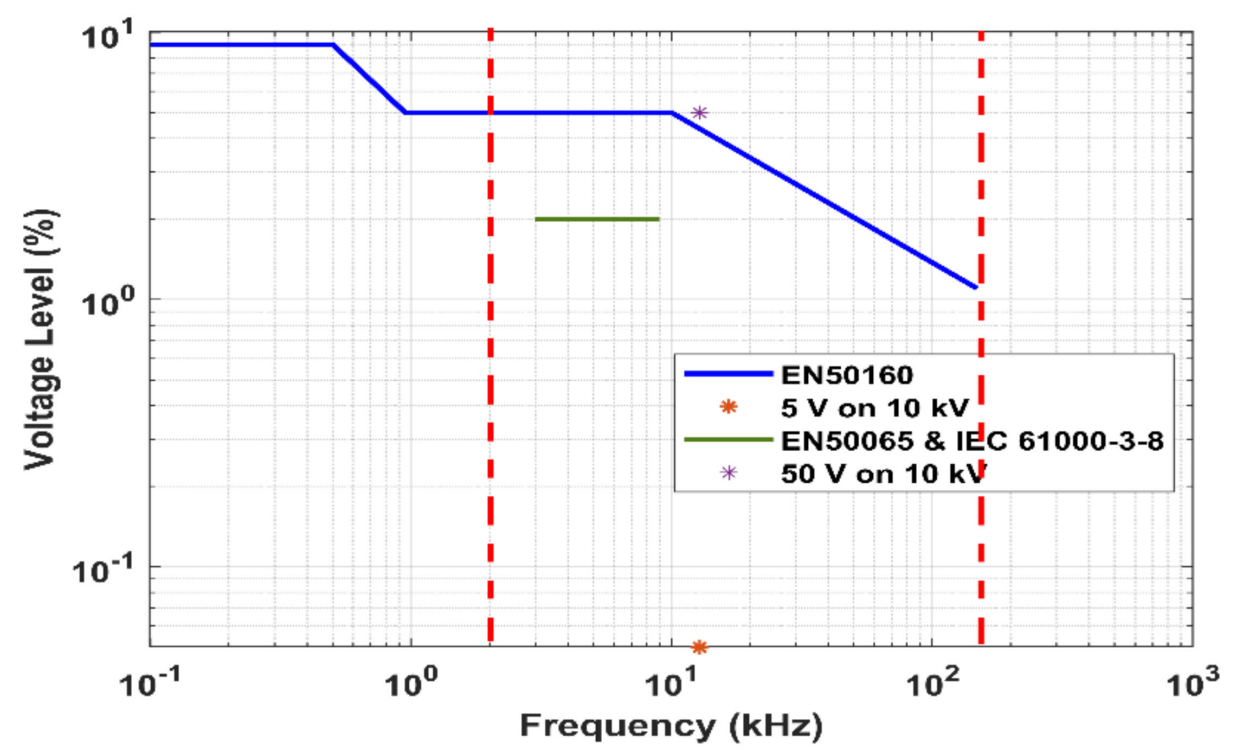

Figure 11. Emission limits at supraharmonics frequency range as per standards.

\section{Conclusions}

The emission limits for higher frequencies $(2 \mathrm{kHz}-150 \mathrm{kHz})$ are of interest among different standardization group. The lack of knowledge about the transfer impedance of the MV network in the supraharmonics frequency range has set limitations to define standards/immunity limits for power converters based supraharmonic sources integrated to the grid.

This work has studied the propagation of supraharmonics in specific MV $\backslash L V$ power grid network configurations. Thereafter, supraharmonic voltages were estimated from measurement and the simulated characteristics of the MV network. The general findings after analyzing the existing MV $\backslash$ LV Swedish network with eight feeders can be summarized as follows:

- The first resonance in the MV network is mainly due to the source and transformer inductance together with the total cable capacitance.

- In the MV network, there are large number of resonances in the supraharmonic frequency range.

- The skin effect provides significant damping, but resonance peaks remain sharp within the supraharmonic frequency range.

- The bigger the MV network, the more resonance frequencies, but also the lower the amplitude of the resonance peaks.

- Measurements close to a wind turbine converter show a time varying emission in the supraharmonics range due to the variation in switching frequency of the wind turbine converter at different operating modes during low power extraction.

- For short feeders as length increases, the magnitude of the transfer impedance at supraharmonic frequency decreases. For further increment in feeder length, the magnitude increases or becomes almost constant. For very long feeders the transfer impedance starts decreasing further.

The amplification of supraharmonics in a network configuration with fewer feeders was high as discussed in Section 4.2. This study helps to better understand the propagation of supraharmonic resonances in MV $\backslash \mathrm{LV}$ networks. With the conclusions of this work and the knowledge about the transfer impedance and resonant peaks in the MV network the possible amplification and expected levels of these emissions in the grid can be predicted. Hence, this study would help standardization committee to set compatibility levels or emission limits for these non-intentional emissions in the MV network. The study can be extended to investigate the aggregation of supraharmonic emission in the MV network 
due to interaction of multiple sources of supraharmonic emissions. Further research could investigate the fault tripping of protection system due to amplified supraharmonics.

Author Contributions: Conceptualization, S.S.L., A.E.D., S.K.R. and M.H.J.B.; methodology, S.S.L.; software, S.S.L.; validation, S.S.L.; formal analysis, S.S.L.; investigation, S.S.L.; resources, S.S.L. and A.E.D.; data curation, S.S.L.; writing—original draft preparation, S.S.L.; writing-review and editing, M.H.J.B.; supervision, S.K.R. and M.H.J.B.; project administration, M.H.J.B.; funding acquisition, M.H.J.B. All authors have read and agreed to the published version of the manuscript.

Funding: This research received no external funding.

Data Availability Statement: Not applicable.

Conflicts of Interest: The authors declare no conflict of interest.

\section{Appendix A}

Table A1. Cable parameters.

\begin{tabular}{|c|c|c|c|c|c|}
\hline Cable & Type/Specification & Zop $(\Omega / \mathbf{k m})$ & L (H/km) & Bsh $(\mu \mathrm{S} / \mathrm{km})$ & $\mathrm{C}(\mathrm{F} / \mathrm{km})$ \\
\hline $\mathrm{C}_{1}$ & $\mathrm{ACJJ} / 150$ & $0.206+0.0754 i$ & $2.4001 \times 10^{-4}$ & 188.5 & $0.6 \times 10^{-6}$ \\
\hline $\mathrm{C}_{2}$ & AXCEL/150 & $0.206+0.0911 i$ & $2.9 \times 10^{-4}$ & 94.248 & $0.3 \times 10^{-6}$ \\
\hline $\mathrm{C}_{3}$ & $\begin{array}{c}\text { AXCL- } \\
\text { OTT3x150/25 }\end{array}$ & $0.206+0.0942 i$ & $2.9985 \times 10^{-4}$ & 94.248 & $0.3 \times 10^{-6}$ \\
\hline $\mathrm{C}_{4}$ & AXKJ/50/16 & $0.641+0.1257 i$ & $4 \times 10^{-4}$ & 62.832 & $0.2 \times 10^{-6}$ \\
\hline $\mathrm{C}_{5}$ & FXKJ/35 & $0.493+0.1068 i$ & $3.3995 \times 10^{-4}$ & 94.248 & $0.3 \times 10^{-6}$ \\
\hline $\mathrm{C}_{6}$ & $\begin{array}{c}\text { AXCL- } \\
\text { OTT3x95/16 }\end{array}$ & $0.32+0.1005 i$ & $3.1990 \times 10^{-4}$ & 94.248 & $0.3 \times 10^{-6}$ \\
\hline $\mathrm{C}_{7}$ & AXCEL/95 & $0.32+0.0974 \mathrm{i}$ & $3.1003 \times 10^{-4}$ & 94.248 & $0.3 \times 10^{-6}$ \\
\hline $\mathrm{C}_{8}$ & AXCEL/50 & $0.641+0.1068 \mathrm{i}$ & $3.3995 \times 10^{-4}$ & 94.248 & $0.3 \times 10^{-6}$ \\
\hline
\end{tabular}

Table A2. Transformer parameters.

\begin{tabular}{ccc}
\hline Transformer & Specification & SC Phase Impedance on LV Side $(\Omega)$ \\
\hline $\mathrm{T}_{\mathrm{M} 1}$ & $16 \mathrm{MVA}, 33 \mathrm{kV} / 11 \mathrm{kV}$ & $0.0397+0.7854 \mathrm{i}$ \\
$\mathrm{T}_{\mathrm{C} 2}$ & $0.5 \mathrm{MVA}, 10 \mathrm{kV} / 0.4 \mathrm{kV}$ & $0.0033+0.0184 \mathrm{i}$ \\
$\mathrm{T}_{\mathrm{C} 3}$ & $0.5 \mathrm{MVA}, 0 \mathrm{kV} / 0.4 \mathrm{kV}$ & $0.0039+0.0181 \mathrm{i}$ \\
$\mathrm{T}_{\mathrm{C} 4}$ & $0.315 \mathrm{MVA}, 10 \mathrm{kV} / 0.4 \mathrm{kV}$ & $0.0069+0.0252 \mathrm{i}$ \\
$\mathrm{T}_{\mathrm{C} 5}$ & $0.5 \mathrm{MVA}, 10 \mathrm{kV} / 0.4 \mathrm{kV}$ & $0.0042+0.0178 \mathrm{i}$ \\
$\mathrm{T}_{\mathrm{C} 6}$ & $0.2 \mathrm{MVA}, 10 \mathrm{kV} / 0.4 \mathrm{kV}$ & $0.0109+0.0323 \mathrm{i}$ \\
$\mathrm{T}_{\mathrm{C} 7}$ & $0.315 \mathrm{MVA}, 10 \mathrm{kV} / 0.4 \mathrm{kV}$ & $0.0072+0.0249 \mathrm{i}$ \\
$\mathrm{T}_{\mathrm{C} 8}$ & $0.4 \mathrm{MVA}, 10 \mathrm{kV} / 0.4 \mathrm{kV}$ & $0.0075+0.0239 \mathrm{i}$ \\
$\mathrm{T}_{\mathrm{C} 9}$ & $0.5 \mathrm{MVA}, 10 \mathrm{kV} / 0.4 \mathrm{kV}$ & $0.0051+0.0185 \mathrm{i}$ \\
$\mathrm{T}_{\mathrm{C} 10}$ & $0.5 \mathrm{MVA}, 10 \mathrm{kV} / 0.4 \mathrm{kV}$ & $0.0043+0.0171 \mathrm{i}$ \\
$\mathrm{T}_{\mathrm{C} 11}$ & $0.5 \mathrm{MVA}, 10 \mathrm{kV} / 0.4 \mathrm{kV}$ & $0.0043+0.0179 \mathrm{i}$ \\
\hline
\end{tabular}

\section{References}

1. Rönnberg, S.K.; Bollen, M.H.; Amaris, H.; Chang, G.W.; Gu, I.Y.; Kocewiak, Ł.H.; Meyer, J.; Olofsson, M.; Ribeiro, P.F.; Desmet, J. On waveform distortion in the frequency range of $2 \mathrm{kHz}-150 \mathrm{kHz}-$ Review and research challenges. Electr. Power Syst. Res. 2017, 150, 1-10. [CrossRef]

2. Bollen, M.; Olofsson, M.; Larsson, A.; Ronnberg, S.; Lundmark, M. Standards for supraharmonics (2 to $150 \mathrm{kHz})$. IEEE Electromagn. Compat. Mag. 2014, 3, 114-119. [CrossRef]

3. Rönnberg, S.K.; Bollen, M.H.J. Propagation of Supraharmonics in the Low Voltage Grid 2 to 150 kHz; Electra Program and Swedish Energy Agency Report; Energiforsk: Stockholm, Sweden, December 2017; ISBN 978-91-7673-461-2.

4. Sakar, S.; Rönnberg, S.K.; Bollen, M.H.J. Interferences in AC-DC LED drivers exposed to voltage disturbances in the fre-quency range 2-150 kHz. IEEE Trans. Power Electron. 2019, 34, 11171-11181. [CrossRef]

5. Paulsson, L.; Ekehov, B.; Halen, S.; Larsson, T.; Palmqvist, L.; Edris, A.-A.; Kidd, D.; Keri, A.; Mehraban, B. High-frequency impacts in a converter-based back-to-back tie; the eagle pass installation. IEEE Trans. Power Deliv. 2003, 18, 1410-1415. [CrossRef] 
6. Kalesar, B.M.; Noshahr, J.B. Capacitor bank behaviour of cement factory in presence of supraharmonics resulted from switching full power frequency converter of generator (PMSG). In Proceedings of the 24th International Conference on Electricity Distribution, Glasgow, UK, 12-15 June 2017.

7. Yalcin, T.; Ozdemir, M.; Kostyla, P.; Leonowicz, Z. Analysis of supra-harmonics in smart grids. In Proceedings of the 2017 IEEE International Conference on Environment and Electrical Engineering and 2017 IEEE Industrial and Commercial Power Systems Europe (EEEIC/I\&CPS Europe), Milan, Italy, 6-9 June 2017; pp. 1-4.

8. Slangen, T.; Van Wijk, T.; Ćuk, V.; Cobben, S. The Propagation and Interaction of Supraharmonics from Electric Vehicle Chargers in a Low-Voltage Grid. Energies 2020, 13, 3865. [CrossRef]

9. Rönnberg, S.K. Emission and Interaction from Domestic Installations in the Low Voltage Electricity Network, up to $150 \mathrm{kHz}$. Ph.D. Thesis, Luleå University of Technology, Luleå, Sweden, 2013.

10. Larsson, A. On High-Frequency Distortion in Low-Voltage Power Systems. Ph.D. Thesis, Luleå University of Technology, Luleå, Sweden, 2011.

11. Klatt, M.; Meyer, J.; Schegner, P.; Koch, A.; Myrzik, J.; Eberl, G.; Darda, T. Emission levels above 2 kHz-Laboratory results and survey measurements in public low voltage grids. In Proceedings of the 22nd International Conference and Exhibition on Electricity Distribution (CIRED 2013), Stockholm, Sweden, 10-13 June2013.

12. Espín-Delgado, Á.; Rönnberg, S.; Busatto, T.; Ravindran, V.; Bollen, M. Summation law for supraharmonic currents (2-150 kHz) in low-voltage installations. Electr. Power Syst. Res. 2020, 184, 106325. [CrossRef]

13. Rönnberg, S.K.; Bollen, M.H.J.; Larsson, A.; Lundmark, M. An Overview of the Origin and Propagation of Supraharmonics (2-150 $\mathrm{kHz}$. In Proceedings of the Nordic Conference on Electricity Distribution System Management and Development, Stockholm, Sweden, 8-9 September 2014.

14. Matthias, K.; Kaiser, F.; Meyer, J.; Lakenbrink, C.; Gassner, C. Measurements and simulation of supraharmonic resonances in public low voltage networks. In Proceedings of the 25th International Conference on Electricity Distribution, Madrid, Spain, 3-6 June 2019.

15. Ma, Z.; Xu, Q.; Li, P.; Wu, J.; Huang, H. Supraharmonics Analysis of Modular Multilevel Converter and Long Cable System. In Proceedings of the 2019 IEEE Sustainable Power and Energy Conference (iSPEC), Beijing, China, 21-23 November 2019; pp. 2585-2589.

16. Noshahr, J.B. Emission phenomenon of supra-harmonics caused by switching of full-power frequency converter of wind turbines generator (PMSG) in smart grid. In Proceedings of the 2016 IEEE 16th International Conference on Environment and Electrical Engineering (EEEIC), Florence, Italy, 7-10 June 2016; pp. 1-6.

17. Blanco, A.M.; Heimbach, B.; Wartmann, B.; Meyer, J.; Mangani, M.; Oeschger, M. Harmonic, interharmonic and suprahar-monic characterisation of a $12 \mathrm{MW}$ wind park based on field measurements. CIRED-Open Access Proc. J. 2017, 677-681. [CrossRef]

18. Mohos, A.; Ladanyi, J. Emission Measurement of a Solar Park in the Frequency Range of 2 to $150 \mathrm{kHz}$. In Proceedings of the 2018 International Symposium on Electromagnetic Compatibility (EMC EUROPE), Amsterdam, The Netherlands, 27-30 August 2018; pp. 1024-1028. [CrossRef]

19. Mumtaz, M.; Khan, S.I.; Chaudhry, W.A.; Khan, Z.A. Harmonic incursion at the point of common coupling due to small grid-connected power stations. J. Electr. Syst. Inf. Technol. 2015, 2, 368-377. [CrossRef]

20. Rönnberg, S.K.; Castro, A.G.; Bollen, M.H.J.; Moreno-Munoz, A.; Romero-Cadaval, E. Supraharmonics from power elec-tronics converters. In Proceedings of the 9th International Conference on Compatibility and Power Electronics (CPE), Costa da Caparica, Lisbon, Portugal, 24-26 June 2015; pp. 539-544.

21. Gil-de Castro, A.; Moreno-Munoz, A.; Garrido, J.; Rönnberg, S.K.; Palacios-Garcia, E.J.; Morales, T. Supraharmonics reduc-tion in NPC inverter with random PWM. In Proceedings of the 2017 IEEE 26th International Symposium on Industrial Electronics (ISIE), Edinburgh, UK, 19-21 June 2017; pp. 1792-1797.

22. Novitskiy, A.; Schlegel, S.; Westermann, D. Analysis of supraharmonic propagation in a MV electrical network. In Proceedings of the 2018 19th International Scientific Conference on Electric Power Engineering (EPE), Brno, Czech Republic, 16-18 May 2018; pp. 1-6.

23. Novitskiy, A.; Schlegel, S.; Westermann, D. Measurements and analysis of supraharmonic influences in a MV/LV network containing renewable energy sources. In Proceedings of the 2019 Electric Power Quality and Supply Reliability Conference (PQ) \& 2019 Symposium on Electrical Engineering and Mechatronics (SEEM), Kärdla, Estonia, 12-15 June 2019.

24. Bengtsson, T.; Dijkhuizen, F.; Ming, L.; Sahlen, F.; Liljestrand, L.; Bormann, D.; Papazyan, R.; Dahlgren, M. Repetitive fast voltage stresses-causes and effects. IEEE Electr. Insul. Mag. 2009, 25, 26-39. [CrossRef]

25. Espín-Delgado, A.; Letha, S.S.; Rönnberg, S.K.; Bollen, M.H.J. Failure of MV cable terminations due to supraharmonic volt-ages: A risk indicator proposal. IEEE Open J. Ind. Appl. 2020, 1, 42-51. [CrossRef]

26. Espín-Delgado, A.; Letha, S.S.; Rönnberg, S.K.; Bollen, M.H.J. Indicators for supraharmonics based on their impact on end-User equipment. Unpublished.

27. Bollen, M.; Mousavi-Gargari, S.; Bahramirad, S. Harmonic resonances due to transmission-system cables. Renew. Energy Power Qual. J. 2014, 712-716. [CrossRef]

28. Dommel, H. Digital computer solution of electromagnetic transients in single and multiple networks. IEEE Trans. Power App. Syst. 1969, PAS-88, 388-399. [CrossRef] 
29. Corcoran, J.; Nagy, P.B. Compensation of the Skin Effect in Low-Frequency Potential Drop Measurements. J. Nondestruct. Eval. 2016, 35, 58. [CrossRef]

30. Wiring Systems for Max 1000 V-Methods of Calculation to Safeguard Correct Disconnection; Svensk Standard SS 42414 05; SEK Swedish Electricity Standard: Kista, Sweden, 1993.

31. Beltran, B.; Benbouzid, M.E.H.; Ahmed-Ali, T. Second-order sliding mode control of a doubly fed induction generator driv-en wind turbine. IEEE Trans. Energy Convers. 2012, 27. [CrossRef]

32. Luo, N.; Vidal, Y.; Acho, L. (Eds.) Wind Turbine Control and Monitoring Advances in Industrial Control; Springer: Berlin/Heidelberg, Germany, 2014; p. 466, ISBN 3319084135. 